\title{
JOSÉ ÁNGEL VALENTE: LA VOZ QUE VIENE DEL DESIERTO
}

\author{
ALFREDO SALDAÑA \\ Universidad de Zaragoza
}

\section{RESUMEN}

José Ángel Valente es autor de una de las escrituras más autoconscientes de la literatura española contemporánea, autoconciencia basada en la incertidumbre y la inseguridad derivadas del lugar absolutamente conflictivo e inestable que ocupa la palabra, cuya materialidad adquiere forma en la promesa de su emergencia o en el riesgo de su desaparición, una escritura, en definitiva, entendida no tanto como una arquitectura perfectamente acabada sino como un escenario de producción incesante de células y semillas de sentido.

Palabras clave: Poesía contemporánea, escritura palimpséstica, indecibilidad, vacío.

\section{JOSÉ ÁNGEL VALENTE: A VOICE FROM THE DESERT}

\begin{abstract}
José Ángel Valente's work stands among the most self-conscious in contemporary Spanish literature. Its self-consciousness is based on both the uncertainty and insecurity produced by the totally conflicting and unstable nature of his word, whose materiality surfaces through the promise of its appearance or the risk of its disappearance. He views poetry not so much as a perfectly polished architecture but as a site for the continual production of cells and seeds of meaning.
\end{abstract}

Key words: Contemporary poetry, palimpsest-like writing, unspeakability, void.

Comenzaré con un juicio de valor: José Ángel Valente —que no dejó de reflexionar a lo largo de su trayectoria sobre las posibilidades y los límites del lenguaje- es autor de una de las escrituras más autoconscientes de la literatura española contemporánea, autoconciencia basada en todo caso en la incertidumbre y la inseguridad derivadas del lugar absolutamente conflictivo e inestable que ocupa la palabra, cuya materialidad adquiere forma en la promesa de su emergencia o en el riesgo de su desaparición, una palabra, por lo tanto, que conoce bien la medida del vacío, ya se trate de un lugar todavía no alcanzado o de un mundo amenazado por la extinción. Si el objetivo de la crítica es localizar el espacio en el que surgen los textos, descifrar y analizar su lugar, esa tarea se presenta bastante compleja en el caso de Valente dado 
que nos encontramos ante una escritura nómada y errante, en permanente fuga de sí misma, una escritura que no cesa de plantear preguntas del tipo ¿qué espacio es capaz de dar acogida al vacío?, ¿qué vocablo utilizar que dé nombre a lo indecible?, ¿cómo dar forma, materia y figura a la nada sin pensarla como algo?, ¿cómo otorgar representación y sentido al silencio?, ¿cómo decir sin decir, cómo hablar al callar?, ¿qué palabra al mismo tiempo no pronunciada ni silenciada se oculta bajo las palabras?, ¿qué rastro, huella o vestigio dará cuenta de una memoria vacía?, ¿cómo darse al retirarse?, ¿a qué abismos y misterios nos enfrenta la revelación poética? He aquí, entre otras, algunas cuestiones que ocuparon a José Ángel Valente a lo largo de su obra literaria, una obra entendida no tanto como una arquitectura perfectamente acabada sino como un escenario de generación incesante de células y semillas de sentido, condenada de este modo a saberse presa de su precariedad y también, paradójicamente, de una infinitud significativa que en ocasiones adquiere la forma de una mise en abîme en la que el lector acaba convirtiéndose en materia textual e iconográfica dispuesta para ser leída e interpretada por quien en un principio era el objeto de su interpretación, como sucede en «De la luminosa opacidad de los signos», poema de Treinta y siete fragmentos (1972) que recrea un proceso de búsqueda de uno mismo en el que el contemplador acaba convirtiéndose en lo contemplado, el intérprete en el objeto de la interpretación, y ello en una estructura circular, especular y abismática que recuerda esa brevísima y fascinante historia a la que Jorge Luis Borges alude en el «Epílogo» de El hacedor (1960) en la que se cuenta el caso de un hombre que - proponiéndose la tarea de dibujar el mundo con todo tipo de imágenes, objetos, animales, instrumentos y personas que fue encontrando a lo largo de su vida- descubre, poco antes de morir, que ese laberinto de líneas traza la imagen de su rostro. Copio ahora el poema de Valente (1989: 55):

En el jeroglífico había un ave, pero no se podía saber si volaba o estaba clavada por un eje de luz en el cielo vacío. Durante centenares de años leí inútilmente la escritura. Hacia el fin de mis días, cuando ya nadie podía creer que nada hubiese sido descifrado, comprendí que el ave a su vez me leía sin saber si en el roto jeroglífico la figura volaba o estaba clavada por un eje de luz en el cielo vacío.

El círculo se cierra con una pregunta que se reescribe a sí misma, prolongando de este modo la interrogación. Así se entiende esta escritura, «clavada por un eje de luz en el cielo vacío», desafiando incluso a quien la dicta, como un proyecto construido en el aire, sobre el alambre del volatinero, como un proceso de vaciamiento radical que ve en la nada y en la ausencia las posibilidades últimas y definitivas de la existencia; en el poema que cierra ese mismo libro puede leerse: «Supo/ [...] /que sólo en su omisión o en su vacío/el último fragmento llegaría a existir» (Valente, 1989: 57). Cabría decir en este sentido que Valente concibió su escritura como una obra en marcha, en cons- 
trucción, y se encontró siempre más próximo de una poética del fragmento que de una poética de la totalidad.

De esta manera J. Á. Valente fue tejiendo una escritura en cierto modo palimpséstica y rizomática en la que filosofía, espiritualidad y literatura (pensamiento, revelación y expresión) comparten un mismo escenario y en la que se aprecian raíces de la mejor tradición castellana de los Siglos de Oro (San Juan de la Cruz, Quevedo), la escritura meditativa y contemplativa (ascéticos y místicos cristianos, judíos y musulmanes), metafísicos ingleses (el propio Valente se ocupó en diferentes lugares de las conexiones entre la mística española y la poesía metafísica inglesa del siglo XVII), el pensamiento oriental (sobre todo, chino y japonés), la tradición hermética, alquímica y cabalística, la poesía de la modernidad (romanticismos alemán e inglés, simbolismo francés, surrealismo) y autores posteriores de la talla de Paul Celan, José Lezama Lima o Edmond Jabès, maestros reconocidos por el poeta gallego. Con unas referencias tan amplias y heterogéneas se teje una «poesía-pensamiento» (Valente, 2004: 52) que atenta contra la línea de flotación del eje esquizoide de parejas de opuestos (materia-espíritu, cuerpo-alma, masculino-femenino, etc.) sobre el que en buena medida se ha construido la cultura y el imaginario occidentales. Comparte incluso planteamientos con un escritor central de la modernidad, relativamente poco citado por Valente en sus escritos teóricos, Stéphane Mallarmé, quien en carta a Henri Cazalis de 28 de abril de 1866 declaró que «nous ne sommes que de vaines formes de la matière» (Mallarmé, 1995: 297) y en cartas a Villiers de L'Isle-Adam de 31 de diciembre de 1865 y 24 de septiembre de 1867 se refirió a la composición «Hérodiade» como un proceso abismático y doloroso en el que se enfrentó a dos absolutos, la Nada y la Belleza —en la segunda de esas cartas encontramos expresiones como «Néant pur» y «vide absolu» (Mallarmé, 1995: 366 y 367), habituales en el discurso crítico valentiano-. No se encuentra, sin embargo, Mallarmé entre los autores a los que Valente tradujo. Cuaderno de versiones (Valente, 2002), volumen que recoge todas las traducciones de poesía realizadas por Valente al castellano y al gallego, incluye versiones de, entre otros, Paul Celan, Louis Aragon, Benjamin Péret, Edmond Jabès, Constantino Cavafis, Eugenio Montale, John Donne, John Keats, Gerard Manley Hopkins y Dylan Thomas y muestra muy a las claras que la traducción no fue ni mucho menos una labor secundaria sino una actividad fundamental en su configuración como escritor, un ejercicio que le sirvió para incrementar su universo lingüístico y al que se entregó con una técnica y una sensibilidad poéticas muy acusadas. Así, ese carácter palimpséstico se aprecia en homenajes, traducciones, comentarios, glosas, actualizaciones lingüísticas, citas, paráfrasis y referencias de otros textos que con frecuencia Valente intercala entre los suyos, actitud que responde a una concepción abierta y dialógica de la tradición literaria en la que su propia obra poética, crítica y de traducción se ven como ramas de un mismo tronco de escritura (además de los autores que tradujo, otros muchos como 
Homero, Catulo, Villon, Shakespeare, Molinos, Rimbaud, Lautréamont, Artaud, Buñuel, Lezama Lima, etc. forman parte de ese amplio y complejo universo de referencias literarias con el que Valente fue tejiendo el suyo propio). Una escritura, de este modo, que aparece en permanente diálogo con otras escrituras hasta el punto de —en ocasiones- desdibujarse la autoría original, singular, la marca de pureza: «La obra es así anónima, como la poesía está, en verdad, hecha por todos» (Valente, 1983: 16). Según Juan Goytisolo (2000), Valente —en lugar de confrontar- complementa y funde los términos antitéticos, aúna las tradiciones opuestas y ello da como resultado un mestizaje poético de alcance extraordinariamente rico y complejo. Aunque son muchos los textos que podrían citarse, tendríamos dos casos extremos en «II», poema de El fulgor que finaliza con la nota «(Memoria de K.)»(Valente, 1988: 10) y que consiste en una traducción de los Diarios de Franz Kafka, en concreto de los apuntes correspondientes al 19 de junio de 1916, y en «Crónica II, 1968», poema de El inocente que se presenta como un «Homenaje a Antonin Artaud», que es, en rigor, una traducción de un fragmento de Le Pèse-Nerfs. Copio a continuación una parte del texto de Artaud (1970, I: 120) y el poema de Valente (1972: 379):

Tous ceux qui ont des points de repère dans l'esprit, je veux dire d'un certain côté de la tête, sur des emplacements bien localisés de leur cerveau, tous ceux qui sont maîtres de leur langue, tous ceux pour qui les mots ont un sens, tous ceux pour qui il existe des altitudes dans l'âme, et des courants dans la pensée, ceux qui sont esprit de l'époque, et qui ont nommé ces courants de pensée, je pense à leurs besognes précises, et à ce grincement d'automate que rend à tous vents leur esprit, - sont des cochons.

Todos los que tienen puntos de referencia en el espíritu, quiero decir de cierto lado de la cabeza, en zonas bien delimitadas del cerebro, todos los que dominan su lenguaje, todos aquellos para quienes tienen las palabras sentido, cuantos creen que existen alturas en el alma y que hay corrientes en el pensamiento, los que son espíritu de la época y han dado nombre a esas corrientes de pensamiento, pienso en sus trabajos precisos y en ese chirrido de autómata que a todos los vientos da su espíritu,

-son unos cerdos.

Y en Fragmentos de un libro futuro, publicación póstuma, pueden leerse, entre otros, los siguientes textos: «Variación sobre un tema barroco», «Versión de Wang-Wei, siglo VIII», «Versión de Takuboku, 1886-1912», «Variación sobre un texto de Bacon de 1952», «Anónimo, versión», «Valleinclanesca», «Orillas del Sar», «Versión de Li Po».

No resulta extraño de este modo que J. Á. Valente apueste por una escritura no monocorde sino orquestal, polifónica, intertextual (y su idea de la intertextualidad rebasa ampliamente el campo literario), cuyo rasgo significativo no viene dado por la pureza melódica y la acumulación de unos mismos registros sino por la alternancia y variación de distintos tonos. Y de quien 
practica un tipo de escritura como ésta podría decirse que, más que un autor (en el sentido tradicional del término), es un simulador, un versionador, un especialista en trasplantes de una tradición literaria a otra; el desafío es considerable: se trata de estar dispuesto a ahogarse en el océano de la colectividad y allí dejar de ser uno mismo para ser alguien con todos, entre todos. No hay mayor ganancia que la que deriva de esta pérdida y, de este modo, Valente apuesta por una poética de la carencia y la quiebra, rasgos inequívocos de una escritura dotada de un alto contenido moral; en este sentido, Valente se sirve de imágenes como la pobreza, la desposesión, la desapropiación y el desasimiento para establecer paralelismos entre la palabra poética y la palabra mística.

Valente se adentra así por un sendero —el de la idealidad vacía y la nada autorreferencial - previamente recorrido por Baudelaire, Rimbaud y Mallarmé, un sendero que le lleva a concebir el poema como presencia y ausencia, vocablo y silencio, puerta que da entrada a un escenario abismal, palabra que «al tiempo que es dicha, ha de quedar siempre a punto de decir» (Valente, 1983: 55), materialización y promesa de diferentes realidades que el texto muestra u oculta entre sus líneas, sentidos satisfechos y posibilidad nunca saciada de sentido — «semilla del sentido» (Valente, 1992: 9)— que remiten a una misma y complementaria idea del texto poético como, a la vez, experiencia consumada y distancia jamás del todo recorrida; el poema, cuya esencia es enigmática, se ve como un generador de múltiples sentidos y su palabra se reconoce no tanto en su fijación como en su alumbramiento y su fluir, no tanto en su prolongada permanencia como en su fulgurante aparición. Así, conceptos como «imposibilidad», «inefabilidad», «indecibilidad», «exilio», «errancia», «blancura», «hueco», «vacío», «nada», «fondo», «abismo», «agujero», «borradura», «disolución»y «silencio» resultan centrales a la hora de referirnos a una poética que ha sabido explorar como muy pocas otras poéticas contemporáneas en las facultades de la lengua y los problemas de la expresión literaria, una poética del despojo y la desnudez que intenta decir lo más con lo menos y donde la palabra aparece siempre a punto de borrarse, incapaz de reconocer finalidad alguna y liberada de cualquier intención predeterminada, una poética de lo inefable enfrentada constantemente al riesgo de la desaparición, articulada como una «experiencia abisal», un desafío del lenguaje a la posibilidad de su propia extinción (Saldaña, 2006). Poesía: palabra que al decirse se desdice, palabra que se hace al deshacerse, palabra que se rompe al construirse y que se desafía a sí misma apuntando hacia un momento anterior o posterior a su propia enunciación, como sucede en este poema de Treinta y siete fragmentos (Valente, 1989: 32):

De la palabra hacia atrás me llamaste ¿con qué? 
Como ha señalado José Luis Pardo (2000), el silencio valentiano no es el silencio vergonzante y cómplice del que calla ante los abusos del poder, ni tan siquiera - aunque coyunturalmente lo haya podido sufrir en alguna ocasión- el silencio impuesto como prohibición o censura; el de Valente es «ese silencio que deja oír el sonido atronador y dulce de un sufrimiento y un goce que no pueden ser convertidos en espectáculo ni en mercadería» (Pardo, 2000: 184). En la escritura poética, vacío y silencio designan un mismo origen y un mismo destino y, frente al habitual tono negro de las letras impresas, el blanco representa el vacío y es la metáfora y el color del silencio, un elemento al que algunos poetas han sabido hacer hablar y ante el que otros han sucumbido cegados por su luz irresistible, anonadados por sus inquietantes y extraños sonidos (analogías fílmicas y plásticas de ese blanco encontramos, respectivamente, en la pantalla de una sala de cine en el momento previo al pase de la película y en el lienzo de un pintor en el instante anterior al comienzo de su trabajo). Es el blanco que rodea al negro de la tinta y que simboliza el vacío en el que estamos sumidos o, por decirlo con palabras de Edmond Jabès, uno de los poetas más admirados por Valente: «Avant et après la parole, il y a le signe/et, dans le signe, le vide où nous croissons» (Jabès, 2002: 96); el blanco, la cegadora claridad de la que surge la epifanía de lo oscuro, el emergente trazo negro de la letra impresa que surge «sobre lo blanco, sobre el vacío esencial» (Valente, 1992: 11), y es un blanco que se encuentra en diversas culturas y religiones (por ejemplo, el taoísmo). Negro sobre blanco, poesía: palabra que al escribirse vive ya (im)presa de su propia impresión, apresamiento al que únicamente la lectura podrá liberar.

Así, la escritura valentiana es —desde sus mismos inicios- plenamente consciente de la inestabilidad del principio sobre el que se asienta: la poesía es conocimiento, aunque nunca conocimiento adquirido de antemano sino conocimiento puesto en juego a cada instante con el riesgo de perderlo o no alcanzarlo (Saldaña, 2007). De una escritura así podría decirse lo que el propio Valente señala del sabio y místico aragonés de origen judío Abraham ben Semu'el Abulafiah de Zaragoza en uno de los textos de El fin de la edad de plata (Valente, 1973: 19): «No tiene tierra y es de toda la tierra», esto es, una escritura apátrida, desterrada, desprovista de origen identitario pero capaz de sentirse como en casa en cualquier lugar (en 1280 - estos son los hechos que narra Valente en «Abraham Abulafia ante portam latinam», el texto citadoAbraham Abulafiah llega a Roma, epicentro de la casa de los cristianos, dispuesto a convertir al judaísmo y a la cábala al papa Nicolás III, hecho por el que es condenado a muerte y condena que evita por la muerte del propio pontífice).

A la luz de estas premisas, la poesía es el lugar de la posibilidad y la lectura poética no ha de entenderse sino como una actividad abierta, crítica e indagadora, capaz de devolver a la palabra el vuelo que la escritura le robó, una actividad en la que todo es posible precisamente porque nada tiene el valor 
de la seguridad, nada está garantizado. Valente se ha referido en distintos lugares a esa actividad (de)constructora de sentidos que es la lectura: «Leer es entrar en el libro, es decir, en el territorio de su infinita posibilidad. Entrar en su blanco, en su silencio o en su vacío. [...] La plenitud del libro es su vacío» (Valente, 2004: 31), una lectura que encontraría su mayor desafío en la página blanca; en «Proyecto de epitafio», poema incluido en Fragmentos de un libro futuro, encontramos desarrollado un motivo que aparece con frecuencia en el último Valente: el proceso de transformación de la vida en un texto descompuesto y fragmentado, y ese proceso supone, por una parte, una aceptación sabia y serena de lo que la muerte y la pérdida implican para quien quiso ser nadie y disolverse en su escritura y, por otra, una defensa apasionada de la lectura como lugar en el que mantener encendida la llama de la vida. Copio íntegro el poema (Valente, 2001: 36):

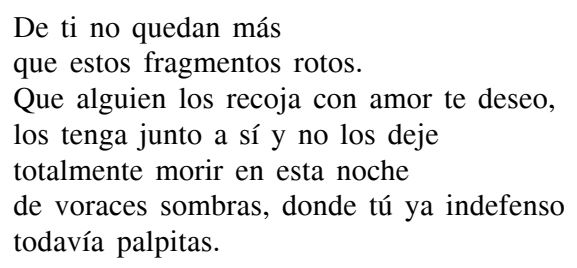

En todo caso, Valente es — desde el comienzo de su trayectoria literariaun poeta obsesionado por dibujar los límites de lo que podríamos denominar «realidad poética» (de ahí sus numerosas composiciones metapoéticas y sus constantes referencias a la poesía como actividad generadora de conocimiento), un poeta, además, que sabe que el lenguaje y el silencio se implican y exigen mutuamente, de tal manera que el primero surge de la ruptura o corte del segundo y que el silencio no rige para sí mismo, es decir, para callarse antes hay que hablar. Y con respecto a una poesía como la suya, de una coherencia y una homogeneidad notables tanto a nivel formal como temático, cabría decir que lenguaje y silencio no solo se implican y exigen recíprocamente sino que llegan a actuar de manera conjunta, compartiendo un mismo escenario dado que la palabra poética, al decirse, esto es, al hacerse — de ahí la expresión «dicho y hecho»-, vive tanto en la manifestación del lenguaje como en la posibilidad de todos los sentidos silenciados, se sitúa en la frontera trazada entre el decir y el callar: «Empieza la palabra poética en el punto o límite extremo en el que se hace imposible decir» (Valente, 2006: 26), paradoja que ocupó un lugar central en el pensamiento literario valentiano. Así, J. Á. Valente (1983: 63), al hilo de obras místicas como las de San Juan de la Cruz o Miguel de Molinos - obras entre las que ve una relación de continuidad y que contempla a la luz de las semejanzas que mantienen con otras obras místicas de Oriente y Occidente-, se ha referido a «esa palabra [poética] que pone en tensión máxima al lenguaje entre el decir y el callar. La pa- 
labra dice así lo que dice, a la vez que dice lo que calla», paradoja propia de la mística al situarse en el lenguaje para — desde allí, con él- tratar de contarnos una experiencia que el lenguaje no puede aprehender, tensión que también encuentra en el lenguaje poético; en un ensayo sobre Jabès escribe: «Hay un difícil equilibrio entre el decir y el callar, entre lo proferido y lo indecible. Toda palabra - sea la del místico o la del poeta - se sitúa en ese escueto filo» (Valente, 2004: 56), y Valente encuentra —antes aun que en Góngora- en San Juan de la Cruz un caso extremo de esa radicalidad de la palabra (poética y mística a un mismo tiempo). Según J. M. Cuesta Abad (2001-2002: 37 ), «en Valente lo poético y lo místico coinciden en una forma de experiencia inmanente a la escritura: el lenguaje se transforma en experiencia única, irreconducible a lo subjetivo y lo objetivo». Poesía y mística comparten de este modo una misma naturaleza heterodoxa, un mismo impulso por cuestionar los dogmas —artísticos o religiosos-imperantes (Terry, 2002), y un ejemplo de ello encontramos en el diálogo que Valente mantuvo siempre abierto con el lenguaje místico de San Juan de la Cruz, cuyo «Cántico espiritual» abonó de imágenes la poesía valentiana.Y con frecuencia a lo largo de su obra literaria ha activado las relaciones entre pensamiento filosófico y experiencia espiritual con la intención de fracturar y disolver el lenguaje e indagar en lo que es el poema: «animal de fondo», dirá Valente (2004: 24), sirviéndose de una expresión juanramoniana, palabra escondida entre las otras palabras, figuras y signos compartiendo con blancos y silencios un mismo escenario.

La oscuridad, la solitud y el silencio nocturnos son los otros rasgos menos conocidos de Xemaá-El-Fná, la plaza de Marrakech en donde la luminosidad, el bullicio, el griterío, el abigarramiento y la excesiva concentración de seres humanos caracterizan lo más peculiar y familiar de ese sitio durante el día. Juan Goytisolo y José Ángel Valente —que compartieron afinidades culturales y mostraron siempre un pronunciado interés por lenguas y tradiciones semitas- encuentran en esa plaza un motivo idóneo para reflexionar sobre el vacío y la suspensión de la mirada, hecho que les llevó a conversar a través de sus textos. Léase, en primer lugar, este fragmento de «Lectura del espacio en Xemaá-El-Fná», capítulo que cierra Makbara, y, a continuación, este otro de «Meditación del vacío en Xemaá-el-Fna»:

Lectura en palimpsesto: caligrafía que diariamente se borra y retraza en el decurso de los años: precaria combinación de signos de mensaje incierto : infinitas posibilidades de juego a partir del espacio vacío: negrura, oquedad, silencio nocturno de la página todavía en blanco (Goytisolo, 1999: 313).

La plaza es, repentinamente, la multitud y su vacío: la desaparición de todos, de todo y del que mira. [...] La multitud no se oye; la mirada no tropieza con la resistencia o la opacidad de los cuerpos. No tropieza. Y deja, a su vez, de ver. [...] «signos de mensaje incierto: infinitas posibilidades de juego a partir del espacio vacío», dices, cuando ya la voz — a punto de extinguirse- y la plaza y la página en blanco son una sola y la misma cosa. (Valente, 1983: 27-28). 
La noche borra lo que el día ha escrito y así deja preparado el escenario que ha de ser trazado y recorrido una vez más a partir del nuevo amanecer; y nada y nadie, vacío y disolución de la identidad, son imágenes tópicas de la descomposición, motivos centrales de un poema como «Deshacimiento», que Valente (2001: 86) dedica a Juan Goytisolo. De un modo similar, la oscuridad y el silencio iniciales de la «página todavía en blanco» —esa «page d'éternité», «page de patience», en expresiones de Jabès (1997 y 2002: 459 y 266) se quiebran cuando el poeta da comienzo a su proceso de escritura: los trazos que dibuja en el papel son manchas que van restando territorio a la oscuridad y al silencio, manchas que oscurecen el blanco de la página y atentan contra su pureza, el silencio en este caso, el discurso que no admite réplica ni vuelta de hoja, el lenguaje más perfecto (si puede decirse así) y, de este modo, al hilo de la escritura de ese «sembrador de preguntas» que fue Edmond Jabès, señala J. Á. Valente (2004: 55): «sabemos que comentar es aprender a callar, generar el silencio en el que el texto habla», es decir, hablar debería enseñarnos a callar, a desandar el camino hacia el silencio originario, hablar tendría que consistir en una práctica de aprendizaje de un progresivo enmudecimiento, debería materializarse en un viaje de alejamiento del lenguaje, en un movimiento de retirada de la palabra, por lo tanto habrá que concluir afirmando -en contra de la expresión común- que el que calla no otorga o asiente sino dice, significa, esto es, el que calla habla, contradicción tan solo aparente que han hecho suya algunos poetas centrales de nuestro tiempo al convertir el silencio en una poderosa herramienta de crítica y cuestionamiento. Y crítica y cuestionamiento de la realidad social encontramos en muchos textos de Valente, por ejemplo en «Sobre el tiempo presente» (1972: 365-367), un poema de El inocente (1970) de largo aliento narrativo que debe leerse en clave política, desmiente la extendida opinión que ve en Valente un poeta solipsista, hermético, encerrado en su particular torre de marfil y muestra, por el contrario, las inquietudes y preocupaciones de un sujeto comprometido con las injusticias y penurias de su tiempo (o léase también, por citar otro poema alejado cronológicamente del anterior, «Redoble por los Kaiowá del Mato Grosso del Sur», incluido en Fragmentos de un libro futuro y fechado por su autor el 13 de junio de 1993). La poesía también es un escenario para expresar clamor ante la opresión y la barbarie y para volcar palabras útiles a los ciudadanos de la tribu, y ello sin necesidad de resultar patético, pedestre o panfletario; todo tipo de inquisiciones y holocaustos, de totalitarismos y atropellos cometidos desde el poder fueron constante objeto de denuncia en la escritura valentiana (véase, por ejemplo, «Hibakusha», ese demoledor poema que cierra Al dios del lugar). Al margen de su actividad literaria, Valente mantuvo siempre una actitud bastante crítica con la realidad social contemporánea; contrario al proceso ciego que representaba la mundialización, percibió con claridad el vaciamiento de la democracia real y el auge de la economía financiera y especulativa en las sociedades occidentales. En una entrevista 
con Nuria Fernández Quesada realizada pocos meses antes de su muerte declaraba: «el final de siglo se anuncia oscuro y la poesía no puede ser ajena a todas estas cosas. La palabra poética es una palabra que se levanta contra todo discurso impositivo y lo invalida» (Valente, 2000: 134-135). Y sin embargo no es la suya una poesía «social» o «realista» en los estrechos sentidos con que estos términos se han utilizado de manera reiterada en nuestra más reciente crítica literaria.

Al hilo de todo esto, conviene recordar que uno de los rasgos significativos de la poesía valentiana es, en palabras de J. L. Pardo (2000: 188), su técnica de «depuración emocional de la palabra» (o «depuración poética de las emociones»), un rasgo que concentra la atención en la propia palabra poética y no tanto en las emociones, sentimientos e ideas que con ella se puedan transmitir; así vive esta palabra, amenazada tanto por la miseria como por la disolución de todo referente extratextual, incluido el autor. La palabra y nada más $\mathrm{o}$, como decía el clásico, all the rest is silence. El silencio, paradoja de la palabra poética, es sin embargo con frecuencia la materia de la escritura, indica los límites de su extensión y abre el camino a su posibilidad, una incierta pero real posibilidad que incorpora el riesgo de su propia imposibilidad; así —desde estos postulados: «Poética: arte de la composición del silencio» (Valente y Tàpies, 2004: 35)— se entienden poemas en los que Valente escribe: «Y el vacío de todo lo creado envolvente, materno, como inmensa morada», «Vienen/desde el vacío las palabras», «Este tiempo vacío, blanco, extenso,/su lenta progresión hacia la sombra» (Valente, 2001: 21, 25 y 100), y de vacíos y ausencias sabía mucho el propio Jabès, para quien la incertidumbre, el abismo, el exilio y el silencio están en la base de la escritura: «La blancura deja un día de ser color, para ser por fin abismo. [...] El abismo es silencioso» (Jabès, 2001: 58 y 74). Y es que el estado natural, original, es lo inefable y mudo. Hablar - escribir también, por lo tanto- supone abrir una grieta en el silencio, una vía de escape por la que el lenguaje se superpone al mundo, implica instaurar, casi siempre, un conflicto. La realidad, que tiene forma de palabra y rebasa tanto a la apariencia como a la experiencia, es el tema de ese conflicto. La escritura ensucia y viola entonces la blancura inmaculada del papel en blanco, da voz a esa misma blancura callada, profana la norma sagrada del silencio, «esa materia oscura» (Valente y Tàpies, 2004: 11) en la que ahonda el poeta - como el músico y el pintor- sin saber qué va a hallar, con la única certeza de estar enfrentándose a una realidad material desconocida, una realidad que dibuja con su presencia el territorio de la escritura, el espacio de lo poético, un lugar/no lugar en construcción que vive bajo la constante amenaza de su propia destrucción, un espacio donde las palabras «todavía esperan/la mano que las quiebre y las vacíe/hasta hacerlas ininteligibles y puras/para que de ellas nazca un sentido distinto» (Valente, 1966: 133). Allí, en soledad, alejado de sus semejantes y de «la sorda letanía cotidiana, la letanía aciaga de la muerte», el poeta indaga en lo oculto de un aguje- 
ro con la pretensión de «encontrar un vacío secreto» (Valente, 1992: 11) y la poesía, en ese instante, no es comunicación sino donación, iluminación, revelación; la palabra poética no dice, la palabra poética emerge, se materializa, se manifiesta y, al hacerse, es. ¿Y qué es?: nada, solo es. Estos versos pertenecen al poema con que se abre Material memoria: «Dime/con qué rotas imágenes ahora/recomponer el día venidero,/trazar los signos,/tender la red al fondo,/vislumbrar en lo oscuro/el poema o la piedra,/el don de lo imposible» (Valente, 1992: 17). Este descenso, como ha explicado el propio Valente (2006), se manifiesta como un rito de iniciación, un viaje de aproximación a la memoria personal, colectiva y de la materia o del mundo. Llegar hasta el fondo de ese agujero no tanto para convertirlo en problema del poema o tema del enunciado sino para hablar desde ahí, construir un lugar que sea a la vez umbral y sepultura de toda enunciación, alumbramiento y disolución del don de la palabra.

Como ha señalado Susana Díaz (2005: 64): «la economía poética valentiana conlleva la exigencia de lo inefable como único destino posible». Es la inefabilidad mística, esto es, la aceptación de la interrupción del discurso cuando se aprende que éste no llega o se queda corto en su decir, discurso vaciado de toda lógica interna y dispuesto en forma de palabras organizadas en torno a «un no sé qué que quedan balbuciendo». «Poesía» e «inefabilidad» aluden en Valente a un mismo imposible; en rigor, inefabilidad - $\mathrm{O}$ «cortedad del decir», en expresión del propio Valente (1971: 63) tomada de Gracián: «cortedad en el decir»— remite a un tópico de la tradición cabalística basado en la insuficiencia o incapacidad del lenguaje para descifrar el mundo, tópico presente en la escritura valentiana desde sus inicios y que han recreado - según recuerda el autor de La experiencia abisal- hacedores de versos como Dante o San Juan de la Cruz. Por esa razón, se trata de un imposible en el que la palabra robada al silencio resulta apropiada para referir esa otra realidad a la que no tiene acceso el verbo de la lógica y el sentido común, y dispuesta para — como señala Valente (1983) — revelarnos una experiencia radical, una experiencia de los límites; palabra escrita, en fin, sobre la «ligne blanche» que traza el itinerario de la libertad, sigue el rastro de la ausencia y el silencio y sabe — como intuyera René Char (1980: 52) — que el corazón de la eternidad habita en el relámpago. Eternidad, conciencia de eternidad en el aquí y ahora, en ese espacio y tiempo irrepetibles.

Nuestra vida es entonces una experiencia de deseo que vacía nuestra existencia hasta el fondo con la intención de colmar luego ese vacío con algún tipo de sentido; de esta manera - diríamos hoy a partir de los trabajos de Derrida-, la poesía practica una singular deconstrucción o un, en expresión de J. Á. Valente (1983: 15), «descondicionamiento» que implica la eliminación de cualquier predeterminación, supone una cierta desubicación por la que han sido abolidas las jerarquías de todos los modelos de referencia, idea a la que vuelve en otro de sus ensayos: «lo poético exige como requisito primero el 
descondicionamiento del lenguaje como instrumentalidad» (Valente, 1983: 52), y es un descondicionamiento que el habla poética comparte con las hablas de la mística y la locura pues todas ellas transgreden el orden sistemático de las convenciones y las significaciones sobre el que el discurso cristaliza y sitúan al lenguaje - y, de paso, a quien lo usa - en su nivel superior de inocencia; se alcanza así un decir puro, sin condiciones, un decir en el que la máxima significación se halla no tanto en lo dicho como en el hecho mismo de decir, desprovisto de cualquier función instrumental, valorado únicamente en su más pura manifestación.

Lenguaje y silencio condenados de este modo a compartir la extensión de un mismo desierto, un espacio atravesado por su vacío: «le désert est distance que soutient le sable» (Jabès, 1997: 550); el desierto, ese lugar heredado probablemente de Jabès que Valente convierte desde el inicio de su trayectoria poética en símbolo de la devastación y la reflexión — «Cruzo un desierto y su secreta/desolación sin nombre./El corazón/tiene la sequedad de la piedra/ y los estallidos nocturnos/de su materia o de su nada» (Valente, 1955: 9) son los versos con que se abre su primer libro, A modo de esperanza, en 1955, mientras que en «Tiempo», uno de sus últimos poemas, fechado el 16 de agosto de 1999, escribe: «Trazo un gran círculo en la arena/de este desierto o tiempo donde espero/y todo se detiene y yo soy sólo/el punto o centro no visible o tenue/que un leve viento arrastraría» (Valente, 2001: 100)—, un desierto que hace frontera con el infinito, es metáfora de la desnudez, la soledad y el silencio, se encuentra atravesado sin embargo por la longitud del habla y cuya medida es la profundidad de su vacío, como muy bien supo el místico y heresiarca aragonés Miguel de Molinos, ese «zahorí del vacío o de la nada» (Valente, 2004: 174); lenguaje, «lindero de tinieblas» (Celan, 1999: 349), claridad cuya linde se ve amenazada por la blanca oscuridad del silencio, lenguaje que comienza cuando el silencio finaliza, silencio que hace acto de presencia cuando el lenguaje se retira y opta por callarse ante la infinitud de este desierto, ese lugar llamado desierto, lugar desierto, vacío, desprovisto de palabras o donde la palabra es signo de lo indecible.

Pero, ¿quién habla cuando el lenguaje habla?, y ¿quién deja de hacerlo cuando el lenguaje es arrastrado hacia el silencio?, cuestiones al fin y al cabo vinculadas con la precaria identidad del sujeto y sus relaciones con el lenguaje y que siempre (pre)ocuparon a Valente: ¿somos nosotros quienes decimos la palabra o es ella la que al pronunciarse nos dice a nosotros? En todo caso, el territorio lírico en el que habitualmente se desenvuelve Valente es el que se describe en un poema como «Tierra de nadie» (Valente, 1972: 184-185), perteneciente a La memoria y los signos (1966): se trata de un lugar indómito, fronterizo, salvaje, no domesticado por el hombre, una «tierra de nadie» en la que la niebla impide ver con claridad la profundidad de sus secretos, el horizonte donde tan solo consiguen adentrarse los «buceadores del vacío»; ahí, en ese lugar donde el lenguaje se ha fracturado — «Palabras incompletas o 
imposibles/signos»—, la soledad, la pérdida y la ausencia son rasgos inequívocos de la vida $y$, al fin y al cabo, parece tratarse de una palabra con un poder extraordinario de revelación, incluso en sus formas de ausencia, inexistencia e imposibilidad, tal como afirma Valente en Tres lecciones de tinieblas, libro de 1980 en el que parece defenderse la idea de que, aun en silencio, somos palabra: «tu propia creación es tu palabra: la que aún no dijiste: la que acaso no sabrías decir, pues ella ha de decirte» (1980: 29), e idea sobre la que vuelve dos años después en Mandorla: «Ahora no sabemos si la palabra es nosotros o éramos nosotros la palabra» (1982: 44). Se trata entonces, en efecto, de un lenguaje genésico, impersonal, del que ha desaparecido toda huella de autoría, todo rastro de identidad, carente de alguien — sea ese alguien, ese sujeto, un dios o un hombre- que se responsabilice del discurso y en el que, por lo tanto, ese alguien ha sido ya suplantado por nadie; un lenguaje, además, amenazado por la súbita e imprevista aparición del silencio. Nadie es quien habla, nada lo que se dice. Pero entender es al fin y al cabo una experiencia íntima, una forma de interiorización en la que el lenguaje ha sido sometido a reflexión por una cierta subjetividad, y en ese proceso, para resultar fructífero, el pensamiento ha de liberarse de todo elemento servil, instrumental o intencional y asumir el riesgo de encontrarse de bruces con la nada, habitar un lugar donde todo está por hacer, en construcción, elaborar un lenguaje donde el no ser de la página en blanco sea el paradigma de la perfección y la pureza. Decir al callar, justo cuando el silencio arrebata su sitio a la palabra.

Poesía: palabra genésica, palabra de Dios, palabra de nadie, palabra que remite al arkhé pero que contiene asimismo la promesa o la posibilidad de un porvenir todavía no alcanzado. La poesía conoce bien la medida del abismo y la desposesión; en ella el sujeto ha desaparecido, se ha hecho presente bajo la forma de una ausencia: «l'écriture est absence et la page blanche, présence» (Jabès, 1997: 305); en ella nada se afirma ni se niega sino que todo surge de un inicial vaciamiento del sentido, allí todo es posible y nada está garantizado, ninguna realidad se asienta, solo el deseo actúa como una línea de fuga que alumbra el camino de un porvenir siempre inalcanzable, como sucede en ese extraordinario y moderno poema medieval en el que Guillermo de Aquitania tematiza la creación a partir de la negación y la nada: «Farai un vers de dreit nien» (1983: 16), la «pura nada» (dreit nien), esto es, algo que no es algo, que se define por su inexistencia, que no se sabe muy bien qué es — «Fait ai lo vers, no sai de cui» (1983: 20) — y que se entrega como una clave para recibir a cambio un nuevo enigma, una contraclave; palabra por palabra, pregunta por pregunta: la poesía no ofrece respuestas sino que se presenta como una fuente generadora de conflictos, interrogantes y desafíos que se encuentran en la nada, en una nada donde descansa el secreto inadvertido y la contraseña no declarada de su más radical sentido. Y un experto conocedor de ese camino hacia la nada fue Miguel de Molinos, «el teórico y el práctico de la quietud, de la aniquilación»(Valente, 2006: 60), a quien J. 
Á. Valente dedicó algunas páginas memorables, entre ellas, un poema — «Una oscura noticia» (Valente, 1972: 389-390), incluido en El inocente- en el que se narra el proceso inquisitorial sufrido por el aragonés ante veintitrés cardenales de la jerarquía eclesiástica romana y que se cierra con estos versos:

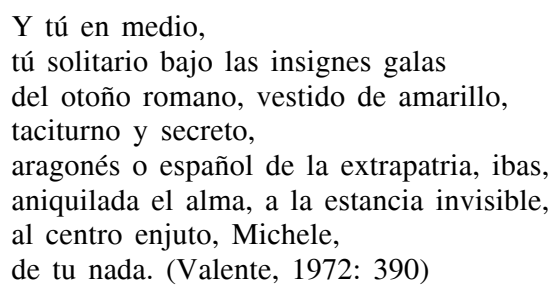

Para el autor de la Guía espiritual y de la Defensa de la contemplación (que murió en 1696 en las cárceles de la Inquisición romana), por ese camino regresamos al estado de inocencia, felicidad, bondad, belleza y perfección: «no mires nada, no desees nada, no quieras nada, ni solicites saber nada, y en todo vivirá tu alma con quietud y gozo descansada» (Molinos, 1989: 171), palabras que pudieran muy bien resumir la enseñanza principal del quietismo (esa doctrina seguida por algunos místicos heterodoxos basada en el anonadamiento de la voluntad y la contemplación pasiva) y que encontrarían su correlato poético en algunos textos de Valente, por ejemplo en este poema de Mandorla en el que la nada se presenta como el estado deseable y la señal inequívoca de toda posesión: «Cuando ya no nos queda nada,/el vacío del no quedar/ podría ser al cabo inútil y perfecto» (Valente, 1982: 43), o en este otro de $A l$ dios del lugar (Valente, 1989a: 67) que es un canto a la inacción, una defensa de la contemplación: «Estar./No hacer./En el espacio entero del estar/estar, estarse, irse/sin ir/a nada./A nadie./A nada».

La poesía - pregunta por pregunta - nada nos garantiza — y si algo puede asegurarnos ello es la seguridad de una total incertidumbre, la promesa de una certera inestabilidad-, nada nos promete y sin embargo en ella cualquier cosa es posible, sobre todo cuando, como sostiene Blanchot al hilo de la escritura de Char, se presenta «como la aventura que ella debe esencialmente ser, cuando se expone, sin garantía ni certidumbre, a la libertad de lo que todavía no está sino por venir» (Blanchot, 1999: 35), una libertad salvaje que aún no ha sido domesticada en la cárcel del lenguaje descrita por Nietzsche, una libertad irrespirable que indica la medida y el horizonte de nuestro ser.

Este proceso de anonadamiento e impersonalización se alimenta de un progresivo descubrimiento de la poesía de Paul Celan, una presencia constante en Valente hasta el final, y supone, en todo caso, una pérdida de protagonismo del sujeto lírico y un replanteamiento de las relaciones entre el lenguaje y la realidad, extremos sobre los que se asienta el espacio poemático. En un texto de La rosa de nadie (1963) escribe Celan: «Una nada/fuimos, somos, seremos/siempre, floreciendo:/rosa de nada,/de Nadie rosa» (Celan, 1999: 162), 
y en «Mandorla», otro poema de ese mismo libro, también ocupa la nada un lugar relevante; se trata de enfrentar a esa nihilidad —en el sentido de «nada hueca, negativa», en expresión de Valente (2004: 203) — una vacuidad poética concebida de modo dialógico y susceptible de ser representada, es decir, a la espera — «ciertamente no siempre muy esperanzadora» (Celan, 1999: 498)de algún tipo de señal, signo o respuesta que la complete; Valente (2004) recuerda que fue Edmond Jabès quien supo escuchar detrás de la lengua del propio Celan el eco nunca apagado de otra lengua. Por otra parte, el poeta gallego publicó en 1979 un texto titulado «Palabra»-incluido en Material memoria - que puede interpretarse como un extraordinario ejemplo de una poética de la desintegración y la vacuidad, sintetiza esa constante aspiración valentiana al silencio y en el que, entre otros versos, leemos: «Palabra/hecha de nada. // Rama/en el aire vacío. // Ala/sin pájaro. // Vuelo/sin ala» (Valente, 1992: 21), enunciado que remite a un escenario aéreo en que el vacío parece haberlo inundado todo, y de 1982 es un libro de poesía titulado precisamente Mandorla que aparece precedido de unos versos tomados del poema homónimo de Celan, hecho nada extraño dada la admiración y el interés que Valente mantuvo siempre por el autor de La rosa de nadie; la mandorla - uno de los símbolos primordiales de la creación, a juicio de Valente (2006) — remite a lo hueco, lo cóncavo, lo vacío —es la «Leere Mandel» celaniana-, al espacio donde se encuentran lo visible y lo invisible, lo uno y lo múltiple, la materia y el espíritu, y caer en la profundidad de la mandorla implica — como en diferentes contextos experimentaron los místicos y los primeros románticos alemanes - no tanto un descenso como una ascensión, un paso adelante en la escala del conocimiento: «Caer fue sólo/la ascensión a lo hondo» (Valente, 1992: 110), bajar a los abismos para contemplar desde allí la luz, entrecruzamiento de lo inferior y lo superior, suma de la extensión de la horizontalidad y la profundidad de la verticalidad. Valente lleva a cabo en este libro una rigurosa exploración sobre el umbral del silencio y la posibilidad del habla, sobre el vaciamiento del espacio y la deconstrucción de la identidad, en uno de los más radicales ejemplos de poética de la nada y del silencio que ha dado la literatura española contemporánea, una exploración que se encuentra presente en libros posteriores del poeta, como sucede en este poema de El fulgor (1984): «Entrar,/hacerse hueco/en la concavidad,/ahuecarse en lo cóncavo» (Valente, 1988: 33), y que ha acabado convirtiéndose en una constante en el pensamiento poético valentiano: «Lo que se comienza por crear es la nada, el principio absoluto de toda creación es la nada [...]. El artista se hace vaciándose de sí mismo» (Valente y Tàpies, 2004: 18), idea sobre la que vuelve en otro lugar: «crear es generar un estado de disponibilidad, en el que la primera cosa creada es el vacío, un espacio vacío» (Valente y Tàpies, 2004: 33 ), es decir, se trata de restar antes que sumar, de suprimir antes que incorporar, de aceptar, en definitiva, que toda conquista debe pagar el precio de la pérdida y la desposesión. Y en la escritura valentiana encontramos poemas en 
los que se relacionan los campos semánticos del silencio y la blancura: «en el primer silencio de la nieve» (Valente, 1982: 37), poemas que —rebosantes de paradojas - hablan de sus mismos lenguajes, desde ellos, y en los que el silencio aludido abre la imposibilidad de la denominación de aquello que resta una vez que el vacío ha concluido su trabajo. Es la poesía entendida como «resto cantable», idea celaniana («Singbarer Rest») que Valente recrea una y otra vez a lo largo de su obra (el motivo es recurrente; aparece, por ejemplo, en «Fénix», de Al dios del lugar, y en «La memoria del fuego», de Variaciones sobre el pájaro y la red). Posible enseñanza: desposeídos de todo, todavía queda una nada imposible de perder que remite a la gran nada primordial, ese principio compartido por algunas corrientes místicas occidentales (piénsese, por ejemplo, en el quietismo) y orientales (el taoísmo).

Ver, de este modo, lo que vive amenazado por la desintegración y se resiste a desaparecer, lo que se encuentra más allá de las llamas, aquello que precisamente la luz oculta, ver y así levantar el velo que impide apreciar lo que se esconde detrás de lo que aparece, distinguir lo que es al margen de lo que parece: «Quedar/en lo que queda/después del fuego,/residuo, sola/raíz de lo cantable» (Valente, 1989a: 25), sobrevivir en los rescoldos tras el paso arrasador de las llamas, significar y significarse con restos y residuos de palabras — «dust of words», decía el Beckett de The Unnamable - una vez que han sido vaciadas de todo elemento tópico y prefijado, llegar siquiera a intuir lo esencial, la «raíz de lo cantable». Una imagen (también una imagen poética) es siempre algo más que una mera imagen, es una refiguración, la huella de un referente que ya es ausencia, que ha sido hecho desaparecer por la propia imagen. Y es que el espacio en el que se ve —esto es, en el que se interpreta y comprende- es un espacio distinto del espacio en el que se mira, es siempre un espacio representado, simulado, y no un espacio real. La poesía se presenta así como una constante reflexión metaliteraria sobre la propia escritura poética como refiguración de la memoria, una cualidad que han hecho suya muchos escritores desde los inicios de la modernidad y que difumina las fronteras entre la teoría y la creación literarias, ámbitos entre los que Valente (2006: 56) siempre vio una vinculación muy estrecha: «El escritor difícilmente puede dejar de reflexionar sobre su propia escritura. Pero la reflexión teórica se forma a partir de la experiencia de creación y no al contrario».

En todo caso, ¿por qué escribir y no su contrario?, ¿por qué empeñarnos en dar al mundo forma de relato, apariencia de discurso? La posibilidad de la escritura implica y contiene su propia imposibilidad, la contemplación de su extremo conlleva el riesgo de su misma desaparición o, como afirma J. Á. Valente (2004: 46), «el límite —o acaso la radical apertura- de cada palabra es la posibilidad de su súbita interrupción», límite, pues, que no cierra ni pone fin a nada sino que, al contrario, abre todas las posibilidades de la palabra, incluida la de su propia extinción; en este sentido, la escritura surge del interior de un discurso suspendido en el aire, hecho de aire, y el fragmento 
se presenta como una modalidad de escritura representativa de una poética caracterizada por la elipsis y la disyunción, y ello ya desde libros como Treinta $y$ siete fragmentos (1972). Voz y palabra (phoné y logos), elementos con los que neutralizar el desafío del silencio —ese «soplo inaudible», en expresión de Foucault (1997: 74)—, desplegados en un escenario dialéctico de conciencias enfrentadas; ahí, quienes detentan la voz tienden a apropiarse también del derecho a la palabra y a la fijación de sus usos (negándoselo de paso con frecuencia a los demás), sabedores de que esa propiedad es decisiva en el control del mundo. A partir de ese instante, logos es algo más que phoné pues implica fluir de sentidos, valores, significaciones, no es una voz sin más sino una voz con mundo. Vivir no es entonces otra cosa que una experiencia política en la que constantemente alguien lucha por significarse y otorgar sentido a la vida entre el aire de las palabras, «en la niebla del lenguaje» (Celan, 1999: 344). Y así decimos que somos en la medida en que creemos romper con la voz los hilos del silencio, atravesar el profundo valle de las sombras y alcanzar el espacio de la luz; caemos hacia lo más alto, ascendemos hacia lo más hondo, J. L. Pardo (2000: 189) lo ha expresado —al hilo de la poesía valentiana - con palabras certeras: «Amanece el canto en el anochecer del cantor. Sólo nos sostenemos cayendo, nos sostenemos en una palabra, pero las palabras caen, y su caída es el canto». Pensamos, al nombrar el mundo, que el discurso nos redime de esa caída, nos libera de la soledad y nos instaura ante los demás, con los otros y, entonces, sobre el espejismo de esas relaciones fundamos nuestra vana e ilusoria existencia, una existencia - como diría Heidegger - infundada, contingente, no elegida, indiscernible de la nada. Resto cantable: palabras que intentan dar forma poética al mundo conservando su memoria, eso que queda después de que el silencio haya concluido su labor erosiva. Sobre esos rescoldos, donde algunos dan por finalizado su trabajo poético, sitúa Valente los fundamentos originarios del suyo.

Según A. Sánchez Robayna (1996), se da en toda la poesía de Valente «una tensión entre autoría y anonimia» que remite a una concepción de la palabra poética en la que ésta «toma cuerpo más allá de toda identidad» (1996: 44), al margen de cualquier conciencia, una anonimia, un vaciado de la personalidad, una impersonalidad que permite la circulación indeterminada e infinita de la palabra en libertad, liberada ya de la servidumbre que supone la referencia a toda autoría. El propio Valente lo ha expresado de esta manera: «Oímos la palabra y volvemos el rostro para ver quién la ha dicho y ya no está» (Valente, 2004: 46), una identidad que se disuelve en la propia palabra, como hace Eurídice al desaparecer ante la mirada involuntariamente aniquiladora de Orfeo. Presencia por ausencia que es ya blancura - palabra que calla la identidad del sujeto que la dice, mirada que ciega la visión del objeto que contempla-, desintegración, vacío, imagen de un paisaje del que ha desaparecido todo rastro de referencia significativa, como sucede en este poema de $A l$ dios del lugar (1989): «Borrarse./Sólo en la ausencia de todo signo/se posa 
el dios» (Valente, 1989a: 19), texto que encuentra su creación o su sentido - o el sentido de su creación - en el borrado y la retirada, y dejar que sea al final el silencio quien nos identifique al acoger en su seno el sentido de la última palabra, ésa que se lee en su omisión y adquiere imagen en su vacío. Así crea Valente el espacio de la creación, el lugar del canto, ese lugar del que ha sido hecho desaparecer toda huella identitaria y donde la palabra es, en su vacío, testimonio de la devastación, promesa de la emergencia. Como afirma E. Jabès (2002: 269): «J'oppose à la vie la vérité du vide», y ya antes Schopenhauer había señalado que el yo es un «vacío sin fondo». ¿Qué hacer entonces?, ¿desandar el camino e intentar un nuevo principio, dar nuevos nombres a las cosas, gritar, callar, atisbar el fondo del abismo, enfrentarse a ese susurro inquietante que es el silencio...? Desde ahí, desde ese hueco sin fondo alguien cuya identidad responde al nombre de nadie hace frente al vacío. Tras Al dios del lugar vendría No amanece el cantor en 1992, una obra que - a juicio del poeta- cerraba un ciclo de escritura dominado por el «descenso a la memoria de la materia» en el que se plantea la ineficacia tanto del lenguaje como del silencio para hacer frente a los acontecimientos radicales, definitivos; en «Paisaje con pájaros amarillos», sección de esa obra escrita a raíz de la muerte de su hijo, puede leerse: «Ni la palabra ni el silencio. Nada pudo servirme para que tú vivieras» (Valente, 1992a: 71). En ese momento Valente sintió la necesidad de liberar los textos que pudiera escribir de ahí en adelante de la servidumbre, las limitaciones y las ataduras del libro (entendido como un proyecto unitario, compacto, cerrado); concibió un plan de escritura al que únicamente la muerte pondría fin y ese plan finalmente tomó cuerpo en Fragmentos de un libro futuro, impresionante y revelador testimonio lírico de un sujeto amenazado por el (paso del) tiempo.

Pocas tareas encontramos tan necesarias como ésa de poner rostro (otorgar sentido) al vacío del que habla Jabès. J. Á. Valente —que algo sabía de voces poéticas en constantes fugas de sí mismas- nos dejó su propuesta acompañada de un aviso para navegantes: «ir más allá de las palabras. La palabra poética empieza justo donde el decir es imposible» (Valente y Tàpies, 2004: 26), y es ahí, en ese lugar situado «más allá de las palabras» donde se encuentra precisamente lo que el lenguaje poético desea nombrar, una propuesta que exige de quienes estén dispuestos a llevarla a cabo el precio de la desposesión, la liberación de todo lastre innecesario, materializada en su caso en forma de escritura poética y teórica y desarrollada a lo largo de casi cincuenta años, una escritura sobria, despojada casi siempre de todo artificio retórico innecesario, reflexiva, meditativa y extraordinariamente eficaz en la transmisión de sus ideas y emociones. El último Valente representa muy bien el caso de ese escritor que, en posesión de «una de las más secretas llaves de la sabiduría» (2000-2001: 15), renuncia a dominar el lenguaje (por considerarla una tarea imposible) y se presta para que el lenguaje hable en él, a través de él. Ha llegado el momento en que ya no es el autor sino el lenguaje quien tiene 
la palabra y, en ese sentido, nos encontramos ante un poeta que se veía inmerso en un ciclo «que se terminará cuando la palabra quiera, no cuando yo lo decida» (Valente, 2006: 43).

De este modo Valente fue orientándose hacia un lenguaje fracturado que hizo de la grieta y la interrupción discursiva, la nada y el vacío sus señas de identidad características, un lenguaje donde únicamente se lee la constatación de la ausencia de la escritura: «La soledad se puebla de fantasmas de papel y de paja, de retratos de nadie, de láminas metálicas, de páginas desnudas donde nada está escrito» (Valente, 2001: 20); y probablemente no haya paradoja mayor que la de cifrar la afirmación de las cosas en la nada, la identidad en nadie (es como si las autoridades competentes se empeñasen en adjudicar un D.N.I. a alguien llamado nadie), un lenguaje desmembrado en el que las palabras fueron desprendiéndose progresivamente de sus significaciones con la única intención de manifestarse, aparecer — sin más- en el poema (es el caso de Fragmentos de un libro futuro, recopilación de sus últimos poemas de la que — no por casualidad - en 1996 se publicó un adelanto con el título de Nadie).

Es la de José Ángel Valente una propuesta poética incompleta e insuficiente pero radicalmente coherente, articulada sobre un lenguaje que no renunció nunca a mantener tensas y conflictivas relaciones con la realidad, con la realidad sancionada por el discurso institucional (de ahí en gran medida el carácter político de ese mismo lenguaje), un lenguaje abierto, descentrado, en construcción, orientado hacia la materialización de cortes, agujeros y vías de escape en el vacío, un lenguaje dispuesto a (re)vivir en todo momento la experiencia del exilio, la otredad y la extranjería, donde la voz del sujeto tiende a diluirse para dar paso a la voz y el rostro del otro, del extraño, del diferente, un lenguaje, en definitiva, elaborado sobre el cruce y el mestizaje culturales y concebido más para plantear preguntas que para ofrecer respuestas, llamado a perseguir el vuelo del alma entre las raíces del viento. Porque si vivir se entiende como una cesión del control de la propia vida para abandonarse en el texto, para dejar que sea la palabra el lugar donde el sujeto se reencarne, y admitiendo como algo cierto el hecho de que «El día en que este juego sin fin con las palabras se termine habremos muerto» (Valente, 2001: 17), la poesía de J. Á. Valente puede leerse como un paradigma de escritura autobiográfica en el que tanto el autor como su vida han sido fagocitados por la palabra, una palabra que ya no se manifiesta en la corpórea fijación de la escritura sino en la intangibilidad del aire, como casi se escucha — podría decirse- en el poema fechado el 25 de mayo de 2000 y que cierra Fragmentos de un libro futuro (2001: 102): "Cima del canto./El ruiseñor y tú/ya sois lo mismo». Así, lo poético designa un territorio (Valente, 2004: 36-40) en el que el ser humano ha sido desposeído de su naturaleza y ha pasado a ser poseído por la palabra, convirtiéndose finalmente en canto, canción, y se trataría de un territorio que la poesía comparte con el cante jondo. 
Según J. L. Pardo (2000: 185), la poesía valentiana se ha radicalizado hasta el extremo de recorrer un itinerario y conseguir situarse «a salvo de toda posibilidad de ser reducida a un juego textual, se ha hecho aún más inasimilable y resistente, se ha emancipado de la propia voluntad del poeta». En el texto que abre Breve son (1968), titulado «La poesía» (Valente, 1972: 249), puede leerse: «Se fue en el viento,/volvió en el aire. // Me llevó adonde/no había nadie», como si se tratara de un lenguaje inasible, no apto para la fijación pero capaz de romper fronteras y trasladarnos a territorios vírgenes, solitarios, desconocidos, un lenguaje dispuesto a nombrar con su palabra la extensión inabarcable de un lugar llamado desierto, un lenguaje ciertamente aporético condenado a merodear sin tregua alrededor de un centro vacío, llamado a buscar, cuestionar, errar, volver a buscar, confundirse en torno a un punto inalcanzable que responde a la imagen de una pregunta. Ahí, en ese escenario desubicado, sin coordenadas, en ese paraje situado más allá o fuera de sí mismo puede darse la posibilidad de un canto que ponga nombre o dote de sentido a la nada. Y una escritura elaborada de esta manera aguarda la (contra)dicción que abre paso al pensamiento y reclama, como probablemente hubiese querido el propio Valente, una lectura insumisa y rebelde, aunque también parcial, inestable y fragmentaria, una lectura entendida como un proceso de (re)producción incesante de sentidos, como una conversación con una obra poética construida a las puertas del silencio.

\section{REFERENCIAS BIBLIOGRÁFICAS}

AA.VV. En torno a la obra de José Ángel Valente. Madrid: Alianza Editorial/Publicaciones de la Residencia de Estudiantes, 1996.

AQUITANIA, Guillermo de. Poesía completa. Cuenca, Luis Alberto de (ed.). Madrid: Siruela, 1983.

ARTAUD, Antonin. Oeuvres complètes. París: Gallimard, 1970. 3 vols.

BLANCHOT, Maurice. La bestia de Lascaux. El último en hablar. Ruiz de Samaniego, A. (trad.); Jiménez, J. (nota de presentación). Madrid: Tecnos, 1999.

CELAN, Paul. Obras completas. Ed. bilingüe. Reina Palazón, J.L. (trad.); Ortega, C. (pról.). Madrid: Trotta, 1999.

CHAR, René. Fureur et mystère. Berger, Y. (pref.). París: Gallimard, 1980.

CUESTA ABAD, José Manuel. «Figuras en fantasma». Prosopopeya, 2001-2002, n. ${ }^{\circ}$ 3, pp. 33-58.

DÍAZ, Susana. [Per]versiones y convergencias. Madrid: Biblioteca Nueva, 2005.

GOYTISOLO, Juan. Makbara. Conte, R. (intr.); Arroyo, E. (dib.). Barcelona: Galaxia Gutenberg, 1999.

—. «Palmera y mandrágora. Notas sobre la poética de José Ángel Valente». En FERNÁNDEZ QUESADA, Nuria (ed.). Anatomía de la palabra. Valencia: Pre-Textos, 2000, pp. 167-173.

—. «José Ángel Valente o la restinga». Rosa cúbica. 21-22, 2000-2001, pp. 180-182.

FOUCAULT, Michel. El pensamiento del afuera. 4. ${ }^{a}$ ed. Arranz, M. (trad.). Valencia: PreTextos, 1997.

JABÈS, Edmond. Le Livre des Questions, II. París: Gallimard, 1997. 
—. El libro de las semejanzas. 2. ${ }^{a}$ ed. Yurkievich, S. (trad.). Madrid: Alfaguara, 2001.

—. Le Livre des Questions, I. París: Gallimard, 2002.

MALLARMÉ, Stéphane. Correspondance complète 1862-1871. París: Gallimard, 1995.

MOLINOS, Miguel de. Guía espiritual. Valente, J. Á. (pról. y notas). Madrid: Alianza, 1989.

PARDO, José Luis. «Carne de palabras». Anatomía de la palabra. FERNÁNDEZ QUESADA, Nuria (ed.).Valencia: Pre-Textos, 2000, pp. 183-193.

SALDAÑA, Alfredo. «Notas para una poética de lo inefable». Quaderns de Filologia. Estudis Literaris, XI, 2006, pp. 177-193.

—. «José Ángel Valente: entre el decir y el callar». En BLESA, T.; Pueo, J. C.; SALDAÑA, A.; SULLÀ, E. (eds.). Pensamiento literario español del siglo XX, 1. Zaragoza: Anexos de Tropelías, 2007, pp. 147-162.

SÁNCHEZ ROBAYNA, Andrés. «Sobre dos poemas de José Ángel Valente». En torno a la obra de José Ángel Valente. Madrid: Alianza Editorial/Publicaciones de la Residencia de Estudiantes, 1996, pp. 41-46.

TERRY, Arthur. La idea del lenguaje. Crespo, Sánchez Robayna y Valente. Santiago de Compostela: Universidade de Santiago de Compostela, 2002.

VALENTE, José Ángel. A modo de esperanza. Madrid: Rialp, 1955.

—. La memoria y los signos. Madrid: Revista de Occidente, 1966.

—. Las palabras de la tribu. Madrid: Siglo XXI, 1971.

—. Punto cero. Barcelona: Barral Editores, 1972.

-. El fin de la edad de plata. Barcelona: Seix Barral, 1973.

—. Tres lecciones de tinieblas. Barcelona: La Gaya Ciencia, 1980.

—. Mandorla. Madrid: Cátedra, 1982.

—. La piedra y el centro, Madrid: Taurus, 1983.

—. El fulgor. 2. ${ }^{a}$ ed. Madrid: Cátedra, 1988.

—. Treinta y siete fragmentos. Domínguez Rey, A. (pról.). Barcelona: Àmbit Serveis Editorials, 1989.

—. Al dios del lugar. Barcelona: Tusquets, 1989a.

—. Material memoria (1979-1989). Madrid: Alianza Editorial, 1992.

-. No amanece el cantor. Barcelona: Tusquets, 1992a.

-. Anatomía de la palabra, Fernández Quesada, Nuria (ed.). Valencia: Pre-Textos, 2000.

—. «En lo más sutil del aire». Rosa cúbica, 21-22, 2000-2001, pp. 14-15.

- Fragmentos de un libro futuro. 2. ${ }^{a}$ ed. Barcelona: Círculo de Lectores/Galaxia Gutenberg, 2001.

-. Cuaderno de versiones. Rodríguez Fer, C. (intr.). Barcelona: Círculo de lectores/Galaxia Gutenberg, 2002.

—. La experiencia abisal. Barcelona: Círculo de Lectores/Galaxia Gutenberg, 2004.

- Palabra y materia. Iglesias Serna, A. (pról. y epíl.). Madrid: Círculo de Bellas Artes, 2006.

—. A. Tàpies. Comunicación sobre el muro. 2. ${ }^{a}$ ed. Barcelona: Ediciones de la Rosa Cúbica, 2004.

Fecha de recepción: 25 de noviembre de 2007

Fecha de aceptación: 25 de junio de 2008 